Produto \& Produção, vol. 17, n.1, p. 32-50,mar. 2016

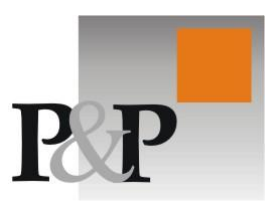

RECEBIDO EM 18/12/2015. ACEITO EM 22/02/2016.

\author{
Gabriel Silva Lima
}

gslima001@gmail.com

Joana Siqueira de Souza

Pontifícia Universidade Católica do Rio Grande do Sul - PUCRS

joana.souza@pucrs.br

Rafael Roco de Araújo

Pontifícia Universidade Católica do Rio Grande do Sul - PUCRS

rafael.araujo@pucrs.br

Ana Paula Beck da Silva Etges

Pontifícia Universidade Católica do Rio Grande do Sul - PUCRS

ana.etges@pucrs.br

\title{
Estruturação de um sistema de custeio baseado no método da UEP aplicada a uma fábrica em realidade virtual
}

\section{RESUMO}

Metodologias para a melhoria da competitividade das empresas exigem avanço de áreas de estudo da Engenharia de Produção. Sistemas de custeio e o uso de Realidade Virtual (RV) englobam as metodologias estudadas a fim de melhor analisar e gerenciar sistemas produtivos de forma a orientar a tomada de decisão, além de complementarem as ferramentas de ensino em sala de aula. Este estudo estruturou um Sistema de custeio, utilizando o método da UEP e do Custo Padrão, para uma fábrica de argamassa desenvolvida em RV pelo LESP. Fez-se a análise de três cenários alternando-se os equipamentos gargalos para identificar-se o impacto no Sistema de custeio gerado. Identificou-se a importância de analisar-se o processo de forma sistêmica, envolvendo o custo unitário do produto, a produção gerada e a lucratividade da empresa e o uso da RV comprovou a importância de analisar-se custos antes de ter a estrutura construída a fim de maximizar o desempenho econômico.

Palavras-chaves: Realidade Virtual, Sistema de Custos, Unidade de Esforço de Produção.

\section{ABSTRACT}

Methodologies for improving the competitiveness of companies require advance study areas of Industrial Engineering. Costing systems and the use of Virtual Reality (VR) include the methodologies studied in order to better analyze and manage production systems in order to guide decision making, and complement the teaching tools in the classroom. This study structured a costing system, using the method of UEP and the Standard Cost for a mortar factory developed in RV by LESP. There was a three scenarios analysis alternating bottlenecks equipment to identify the impact generated in the costing system. It identified the importance of analyzing up to systemically process involving the unit 
cost of the product, the generated production and profitability of the company and the use of RV proved the importance of analyzing up costs before having the structure built order to maximize economic performance.

Keywords: Virtual Reality, Cost Accounting Systems, Production Effort Unity.

\section{Introdução}

O ambiente atual no qual as empresas estão inseridas está mais competitivo, o que afeta diretamente os seus sistemas produtivos. Consequentemente, entre as preocupações das empresas está a busca por melhorar constantemente a eficiência e a produtividade dos seus processos, evitando ineficiências e mantendo-se competitivas no mercado (BORNIA, 2010).

A competitividade aliada à atual demanda para reduzir o custo e o tempo envolvido, desde a criação de um produto até a sua produção, vêm fazendo as empresas utilizarem novas tecnologias na área da manufatura para auxiliar no apoio à tomada de decisão. A Realidade Virtual (RV) tem como uma de suas utilidades evitar problemas antes de sua ocorrência, prevenindo erros custosos à produção (MUJBER et al., 2004). A sua aplicação vem crescendo e se tornando um importante tópico de estudo para futuros engenheiros, pois motiva os estudantes no aprendizado em sala de aula permitindo que apliquem ferramentas aprendidas de forma prática (HAFNER et al., 2013).

Estruturar sistemas de custeio engloba o escopo de habilidades da engenharia, dado que através deles pode-se gerenciar custos e orientar a produção industrial a níveis mais eficazes e lucrativos de produção. A utilização de um sistema de custos que permita a identificação e a quantificação de desperdícios gerados pela empresa, torna-se uma ferramenta essencial para a melhoria da eficiência dos processos produtivos (BORNIA, 2010). Em muitos casos as informações providas de um sistema de custos são consideradas estratégicas para a tomada de decisão das empresas, auxiliando os gestores no gerenciamento dos custos decorrentes dos processos e atividades (BEUREN et al., 2003).

Nesse contexto, este trabalho tem como tema o desenvolvimento de um sistema de custeio para uma fábrica em Realidade Virtual desenvolvida pelo Laboratório de Engenharia de Sistemas de Produção (LESP) da Pontifícia Universidade Católica do Rio Grande do Sul (PUCRS). A fábrica foi desenvolvida pelo LESP com o intuito de aproximar a realidade fabril ao contexto educacional, possibilitando aos alunos uma imersão quase prática do ambiente fabril e uma vivência de simulações práticas antes mesmo de vivenciá-las no dia-a-dia do trabalho. Sendo assim, a motivação da escolha desse tema gerou-se a partir da necessidade de implementar um sistema de custeio para a fábrica em RV como forma de aprendizado diferenciado aos alunos da Engenharia de Produção, possibilitando uma imersão da realidade prática dos custos aplicados a uma fábrica, o que muitas vezes não é vivenciado por parte dos alunos. Segundo Hafner et al. (2013), a RV vem sendo cada vez mais utilizada como forma de ensino para estudantes que querem estar bem preparados para o mercado de trabalho.

Assim, o objetivo geral deste trabalho é estruturar um sistema de custeio aplicado a uma fábrica em RV desenvolvida pelo LESP/PUCRS. Os objetivos específicos são: (i) criar cenários no processo produtivo da fábrica com a alteração de equipamentos; (ii) avaliar o impacto dos diferentes cenários no desempenho da empresa, através do seu sistema de custeio; e (iii) gerar uma base de dados de custos da fábrica para ser utilizada como forma de aprendizado em sala de aula.

O trabalho apresenta as seguintes delimitações: $(i)$ os Métodos de Custeio aplicados foram o Método da Unidade Esforço de Produção (UEP) e Custo Padrão; (ii) os dados de previsão de produção utilizados para o Sistema de custeio não foram questionados; (iii) o trabalho desconsiderou a utilização de aditivos na formulação de argamassa; (iv) por se tratar de informação sigilosa de cada fabricante, o traço da argamassa foi estimado pelo LESP por professor especializado; $(v)$ o escopo do trabalho limita-se ao processo de extração da pedra calcária até o ensaque do produto final (argamassa); e ( $v i)$ para o cálculo do Custo Unitário não foram considerados os Custos Indiretos, somente os Custos de 
Transformação, assim como não foi considerado a abordagem de impostos para calcular a Margem Parcial Bruta.

\section{Referencial Teórico}

Nessa seção é abordado o conceito de RV, assim como seu avanço ao longo do tempo e suas aplicações na indústria e ensino da Engenharia. Outro tema a ser abordado é o Sistema de custeio como um todo e seu detalhamento em Princípios e Métodos de Custeio.

\subsection{Realidade Virtual}

A elevada customização, qualidade e agilidade exigida pelo mercado demanda que empresas atuem de forma eficaz no desenvolvimento de seus produtos e serviços. Nesse sentido, a RV recebe atenção das empresas, por permitir que erros sejam previamente identificados através de sistemas computacionais (KLINGSTAM; GULLANDER, 1999). A RV permite ao usuário percorrer através da tela do computador dentro de uma realidade tridimensional (3D) (MUJBER et al., 2004). Essa interação tridimensional permite o usuário manipular e explorar dados em tempo real de forma altamente interativa. A RV tem ampla aplicação no setor industrial, sendo utilizada desde o planejamento de fábricas, na simulação da manufatura, validação de prototipagem e no treinamento de funcionários (NETTO, 1998).

Com o avanço tecnológico na área computacional, a RV vem contribuindo eficientemente nas suas diversas aplicações (ABULRUB et al., 2011). A manufatura é uma das várias aplicações da RV, a qual, quando aplicada a esse contexto, é definida como um sistema de computador que é capaz de gerar informações sobre a estrutura, status e comportamento do sistema de produção, assim como pode ser observado em um ambiente de produção real (KLINGSTAM; GULLANDER, 1999). Os avanços na tecnologia da RV na última década têm fornecido o impulso para a aplicação em diferentes áreas da Engenharia, como design de produto, modelagem, controle da área fabril, simulação de processos, planejamento de produção, treinamento, testes e verificação (ABULRUB et al., 2011). A RV não somente permite um ambiente de realidade 3D, mas também interage com objetos para melhorar a tomada de decisão das perspectivas qualitativas e quantitativas (MUJBER et al., 2004).

A RV oferece aos engenheiros uma nova maneira de não somente visualizar os seus problemas, mas também interagir com o ambiente para resolvê-los de forma eficaz e eficiente. A visualização combinada com a interação aumenta a capacidade de decisão de engenheiros, melhorando a qualidade e diminuindo o tempo de desenvolvimento de novos produtos (MUJBER et al., 2004).

A RV está sendo amplamente utilizada pelo setor industrial e se tornando uma ferramenta acessível aos usuários. Com esse acesso mais próximo da RV, estudantes que querem estar preparados para o mercado de trabalho, estão cada vez mais interessados em cursos que proporcionem o uso de simulações didáticas sobre a prática de mercado (HAFNER et al., 2013). Segundo Tiruvannamalai et al. (2004), ensinar alunos com pouca experiência fabril é uma tarefa difícil devido aos diversos conceitos envolvidos, tornando o assunto entediante para muitos alunos que ainda não visitaram uma fábrica. A criação de um modelo de RV interativo, fornece aos alunos a oportunidade de visualizar os conceitos e metodologias fabris de forma mais prática (ABULRUB et al., 2011). A RV tem potencial para incentivar os alunos a passar mais tempo em sala de aula, capturando e mantendo o interesse pelo estudo nas diversas áreas de concentração dos cursos (TIRUVANNAMALAI et al., 2004, WHITMAN; CHAPARRO, 2006).

Alguns casos que apresentam a aplicação da RV são em pesquisas de engenharia para extração de óleo (HUI et al., 2012), em projeto e desenvolvimento do processo de produção de um sistema de mineração mecanizada (XIAOQIANG et al., 2011), na criação de protótipos de ambientes da construção civil (GOULDING et al., 2012), na modelagem de processos de projeto automatizado (SUNG et al., 2009) e em empresas de tecnologia da informação que criam ambientes que permitem aos alunos avaliar as decisões tomadas e como estas afetam os negócios (RAINSFORD, 2005). 
A construção dos modelos virtuais e a programação destes modelos em 3D necessita de softwares específicos, alguns gratuitos como o software Blender, que tem sido utilizado em larga escala para modelagem de objetos 3D (HAGUENAUER et al., 2008, MARTINS; GUIMARÃES, 2012, MONNERAT et al., 2012) e o Unity 3D, criado para auxiliar no desenvolvimento e programação de jogos (game engine) e atualmente aplicado ao desenvolvimento de plataforma virtuais de ensino (BARATA, 2010, SILVA; SILVA, 2011).

Outro sistema computacional existente para se simular o processo produtivo é o ProModel. Este apresenta uma interface gráfica e permite analisar qualquer tipo de sistema produtivo com animações de forma computacional, além de fazer uma interface com técnicas estatísticas a fim de permitir a otimização o processo simulado (BENSON, 1997). Entre as principais contribuições da aplicação da simulação computacional através do ProModel, tem-se a redução de custos, aumento da capacidade produtiva e melhora no nível de serviço, devido a análise antecipada da solução ótima de modelo de produção que é viabilizada através do software (HARRELL; PRICE, 2003).

Além da aplicação na indústria o uso do ProModel como ferramenta de ensino tem se disseminado. Powell (2005) influenciado pelo distanciamento dos alunos do processo produtivo, avaliou a influência que o uso de ferramentas computacionais que permitem a modelagem do processo remete no entendimento dos conceitos produtivos por alunos de graduação. $\mathrm{O}$ resultado comprovou que todos os envolvidos no estudo se mostraram mais motivados e aproximados dos conceitos produtivos, sendo sugestão do estudo a inclusão na grade curricular de disciplinas utilizando simulações de processo produtivo através de computadores. No contexto brasileiro, universidades têm implementado o uso conjunto do ProModel com demais disciplinas e ferramentas estudadas ao longo da engenharia industrial. Lima et al. (2012) em um laboratório de pesquisa utilizando RV modelaram um processo de manufatura no ProModel para explorar a capacidade de uso de ferramentas de qualidade e de melhoria de eficiência do processo produtivo dos alunos de graduação. Os autores concluem salientando o valor no aprendizado gerado aos alunos, que quando distantes de um processo real, passaram a compreender melhor o fluxo produtivo, mencionando que um dos pilares para a excelência de um curso de Engenharia Industrial pode ser a união de alunos e professores em pesquisas que usufruem de sistemas computacionais.

\subsection{Método da Unidade Esforço de Produção (UEP)}

O método da Unidade Esforço de Produção (UEP) procura solucionar a problemática, da apropriação dos custos de transformação, por meio da unificação da produção, através de uma medida que sirva como base de comparação direta entre os produtos e os processos de fabricação (FADANELLI, 2007).

Cambruzzi et al. (2009) afirmam que o método da UEP, além de propiciar o custo de transformação dos produtos, disponibiliza outros subsídios extremamente importantes na gestão industrial, à medida que propicia a análise de cada etapa do processo produtivo. Apesar de ser um método de custeio com aplicação no processo produtivo fabril, os benefícios do UEP refletem além das áreas produtivas. Sakamoto (2003) em seu estudo cita alguns benefícios proporcionados por esse método na controladoria de gestão e no planejamento e controle da produção, como direcionadores de custos de transformação comuns, análise de processo e produtividade, custo por processo, divisão de responsabilidades e estruturação do custo de produção. Segundo Cambruzzi et al. (2009, pag. 7),

A noção de esforço de produção possui uma característica que lhe confere uma grande força, que é a homogeneidade. A característica da homogeneidade permite que se possa afirmar que quaisquer que sejam os produtos fabricados e seus respectivos processos de fabricação, a produção destes produtos necessita de esforços de produção de mesma natureza, embora de diferente intensidade, e é exatamente porque os esforços de produção são de mesma natureza que estes podem ser adicionados, qualquer que seja o produto considerado na fábrica.

Zonnato et al. (2010) constataram em seu estudo a precisão do método na identificação dos custos de reciclagem da empresa pesquisada, em que os custos de transformação identificados através do método representavam um valor próximo dos custos apurados pelos gestores. Além disso, o método 
da UEP proporcionou uma visão abrangente da linha de produção e, como consequência, foi possível identificar as limitações da capacidade produtiva.

Segundo Kunh et al. (2012), a grande vantagem da Unidade de Produção refere-se ao fato de o gestor ter uma maior clareza e precisão de quais produtos podem gerar maior rentabilidade e quais produtos apresentam menor, assim identificando os produtos de menor potencial de ganho, podendo desenvolver trabalhos de melhoria.

O procedimento para aplicação desse método consiste em duas fases, a implantação e a operacionalização. A fase de implantação consiste em cinco etapas, sendo a primeira a divisão da fábrica em Postos Operativos (PO). Na segunda etapa, deve-se determinar os Índices de Custo horário $(\$ / \mathrm{h})$ por $\mathrm{PO}$, isto é feito através da divisão do custo mensal (\$) de cada $\mathrm{PO}$ por sua respectiva capacidade padrão (h). Na terceira etapa, deve-se definir o Produto-Base da empresa, o qual deve ser um produto que passe por todos os POs ou até mesmo um produto fictício que represente o uso da estrutura pelos produtos da empresa. Na quarta etapa, deve-se calcular os Potencias Produtivos (\$/UEP) de cada PO, o que é feito através da divisão do FIPO do PO pelo custo de fabricação de um produto base. Na quinta etapa calcula-se então os chamados Equivalentes dos Produtos em UEP, que representam quanto cada produto necessita de esforço para ser produzido (UEP/un).

Já na fase de operacionalização, faz-se a mensuração da produção total em UEP, que é calculada conforme a equação (1).

$$
\text { Valor } U E P=\frac{C T}{\text { Produção real }}
$$

(1)

onde:

CT = Custo de Transformação do período em análise da linha de produção

Produção real $=$ somatório dos Equivalentes dos Produtos multiplicados pela quantidade de produtos produzidos no período em análise.

Após pode-se calcular o custo realizado de produção de cada produto, multiplicando seu equivalente de produto pelo valor da UEP encontrado na Equação (1) (WERNKE, 2004).

Por fim, faz-se a medição de desempenho através de três indicadores: Eficiência (Equação (2)), Eficácia (Equação (3)) e Produtividade Horária (Equação (4)). Através destes indicadores é possível identificar pontos de melhoria na fábrica, identificando os PO que podem operar em melhores níveis de produção.

Eficiência $=\frac{\text { Produção real }}{\text { Capacidade teórica }}$

Eficácia $=\frac{\text { Produção real }}{\text { Capacidade prática }}$

Produtividade horária $=\frac{\text { Produção } \text { real }}{\text { Capacidade } \text { prática }}$

A UEP está aplicada em diversas indústrias brasileiras em conjunto com outros métodos de custeio formando os sistemas de custos de diferentes ramos da manufatura (FILOMENA et al., 2011). Uma das justificativas para adoção do método nos custos diretos de transformação está relacionado ao conceito de esforço: o foco principal do método não é encontrar o custo de fabricação dos produtos, mas o esforço que a indústria realiza para produzi-los, de modo que a identificação de postos ineficazes e improdutivos passa a ser viável (FADANELLI, 2007). Filomena et al. (2011) propuseram como um sistema de custos para ambientes de manufatura o uso conjunto dos métodos UEP, ActivityBased Costing (ABC) e Custo Padrão. Os autores comprovaram através de uma aplicação prática o sistema proposto e salientaram os ganhos em gestão passíveis de custos em indústrias que passam a adotar sistemas híbridos de custeio, devido a capacidade que eles permitem de identificar-se ineficiências. 


\section{Procedimentos Metodológicos}

O estudo apresenta as características de natureza do tipo pesquisa aplicada, apresentadas por Vergara (2005), uma vez que a pesquisa foi motivada pela necessidade de resolver um problema concreto e não apenas no nível teórico, mas sim com uma finalidade prática. A pesquisa aplicada envolverá a estruturação de um Sistema de custeio para uma fábrica de argamassa desenvolvida em Realidade Virtual pelo Laboratório de Engenharia de Sistemas de Produção da PUCRS, que será utilizada pelos estudantes do curso de Engenharia de Produção, simulando cenários e avaliando os seus impactos. Trata-se de uma abordagem quantitativa, devido a utilização de números para detalhamento dos resultados encontrados (SEVERINO, 2007).

O objetivo deste estudo é exploratório, por proporcionar familiaridade com o problema à vista e torná-lo explícito, envolvendo levantamento bibliográfico. Segundo Marconi e Lakatos (1999), os estudos exploratórios têm como objetivo o levantamento de um problema ou questão com as finalidades de desenvolvimento de hipótese, aumento da familiaridade do pesquisador com o assunto pesquisado e modificação e clarificação de conceitos. O procedimento se caracteriza como uma Pesquisa-ação, uma vez que os pesquisadores estiveram envolvidos diretamente e de forma cooperativa no problema de pesquisa (KAUARK et al., 2010).

O Método de trabalho é composto por cinco Fases e suas etapas, conforme Figura 1. Percebese que o método da UEP é elemento central da metodologia proposta, a qual por sua vez possui etapas anteriores de levantamento de dados e posteriores de análise. A fase III representa o método da UEP conforme sugerido por Bornia (2010). As fases I e II dão suporte para a execução do método da UEP e para a fase IV através do entendimento do processo e levantamento de dados. A fase IV utiliza as informações da UEP e permite o cálculo do custo unitário da argamassa.

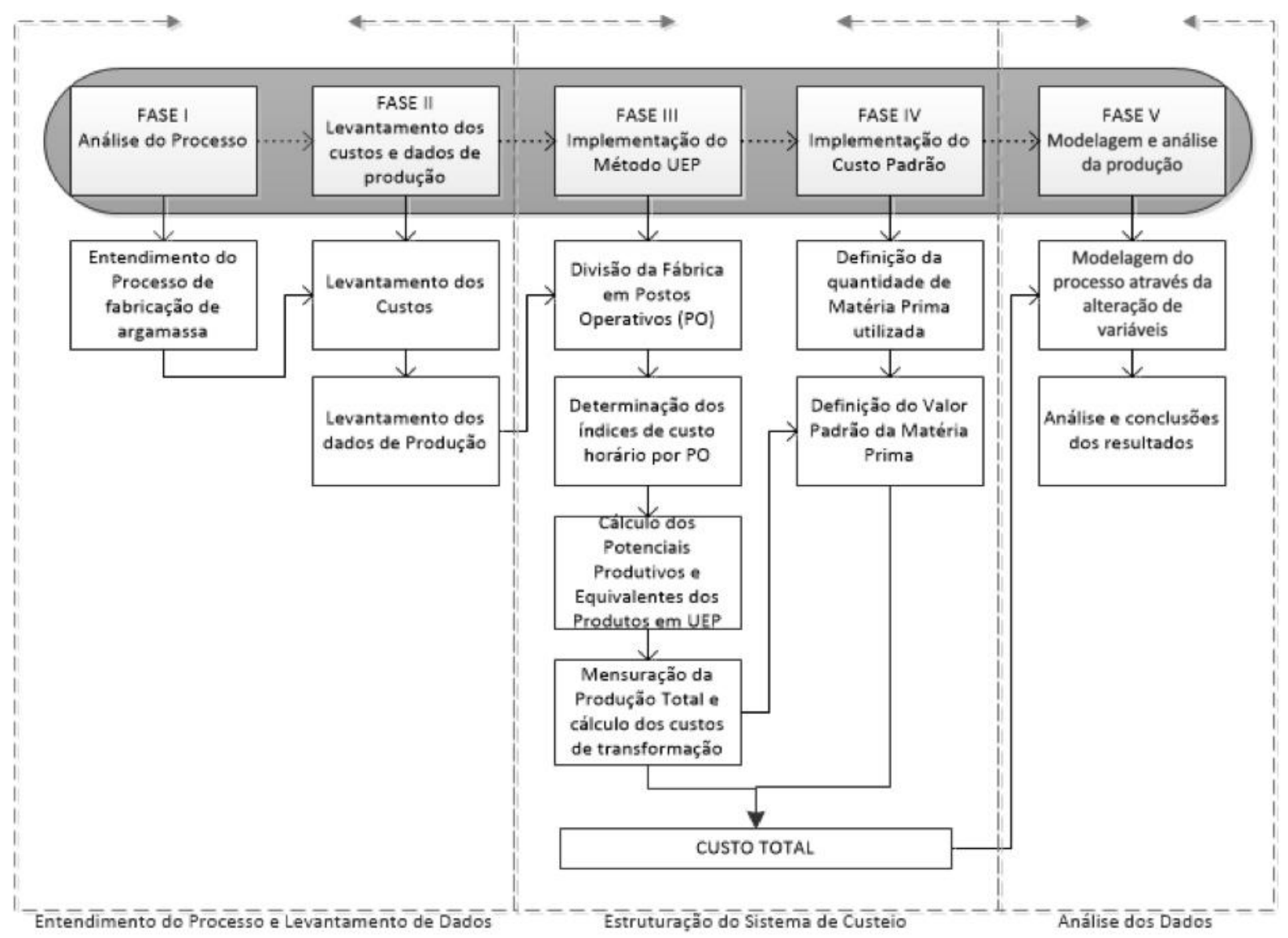

Figura 1 - Fases e etapas do Método de Trabalho

Fonte: adaptado de Wernke (2004) e Bornia (2010) 
Na primeira Fase foi realizada a análise do processo através do entendimento do processo de fabricação de argamassa da fábrica em Realidade Virtual desenvolvida pelo LESP/PUCRS. Na segunda Fase foi realizado o levantamento de todos os custos envolvidos no processo como custos de mão-de-obra direta e indireta, depreciação dos equipamentos, manutenção, materiais de consumo e energia elétrica. Após essa etapa foi realizado o levantamento dos dados de produção utilizando como insumo a modelagem do sistema produtivo realizada pelo LESP através do software de simulação computacional ProModel.

Com os dados de produção levantados, inicia-se a terceira Fase referente à implantação do Método UEP, através da divisão da fábrica em Postos Operativos e a determinação dos Índices de Custo, cálculo dos Potenciais Produtivos e mensuração da produção total, calculando-se os Custos de Transformação. Na quarta Fase, definiu-se a quantidade de matéria prima a ser utilizada por tipo de Argamassa (traço da argamassa) e considerou-se como insumo a definição dos custos unitários de fabricação das matérias primas areia média e fina, definidos através da UEP, para calcular o Custo Padrão da argamassa, definindo assim o Valor Padrão. Com o Custo Padrão e o Custo de Transformação dos produtos calculados tem-se o Custo Total Unitário de cada produto.

$\mathrm{Na}$ quinta e última Fase foi realizada a modelagem e análise dos resultados, através da alteração de variáveis do processo, como a demanda e equipamentos do processo. Para finalizar essa Fase foi realizado o levantamento dos dados encontrados para fins de análises e conclusões.

\section{Estruturação do Sistema de custeio}

$\mathrm{Na}$ sequência serão apresentadas e discutidas cada Fase da metodologia proposta, apresentando-se os resultados finais gerados.

\subsection{Fase I - Análise do Processo}

Para que a implementação do sistema de custeio fosse realizada, foi necessário analisar e entender o processo da fábrica modelo utilizada pelo LESP para a modelagem em RV. A fábrica em questão produz três tipos de argamassa: colante (P1), reboco (P2) e contrapiso (P3). Sendo a diferença entre os três produtos, a quantidade comercializada e o tipo de matéria prima utilizada: areias, cimento e cal. O processo de fabricação está dividido em cinco módulos: módulo de mineração, de moagem, de secagem, de estoque e mistura/ensaque, conforme ilustrado na Figura 2.

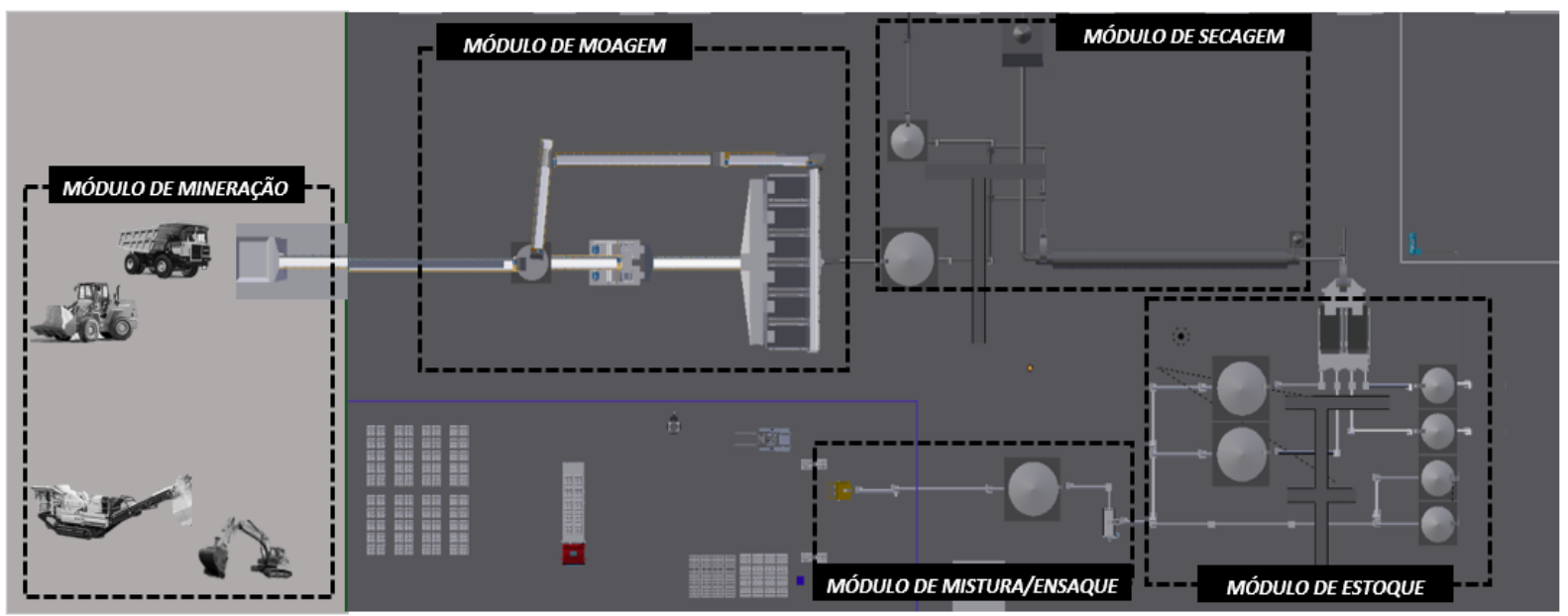

Figura 2 - Processo de fabricação de argamassa

Os módulos de mineração, moagem e secagem são responsáveis pela fabricação da matéria prima areia, que podem ser fina, média, grossa ou filler (pó da areia fina oriunda do processo, porém não utilizado para a fabricação de argamassa). No módulo de estoque estão armazenados em silos as 
areias, o cimento e o cal, sendo os dois últimos adquiridos via fornecedor. O módulo de mistura e ensaque é responsável pela mistura das matérias primas transformadas nessa etapa em argamassa, que é ensacada para comercialização.

O módulo de mineração está instalado a $3 \mathrm{~km}$ da fábrica e é onde ocorrem as explosões da jazida de calcário três vezes por semana, gerando aproximadamente 400 toneladas de pedra calcária, que tem sua granulometria diminuída através do britador e após levada por um caminhão para a fábrica para a moagem. No módulo de moagem, o material passa por dois moinhos de martelo, onde diminui ainda mais a sua granulometria. Na sequência, através de esteiras, passa para as peneiras vibratórias, onde os materiais que apresentam granulometria suficiente de acordo com os padrões estabelecidos seguem à próxima etapa. $\mathrm{O}$ material que não está com granulometria suficiente retorna para o moinho de martelo, através de uma esteira de retorno. Após as peneiras, o material, já nessa fase considerado como areia úmida, entra no módulo de secagem, onde é processado pelo secador, composto por gerador que produz ar quente por mecanismo de chama alimentado por cilindros de gás GLP, retirando a umidade do material à medida que esse passa pelo equipamento. A areia, agora seca, sai do secador e passa em duas peneiras paralelas, cada uma com quatro malhas para separação do tipo de areia, onde é dividia em areia fina, média, grossa e filler em cada nível da malha das peneiras. $\mathrm{O}$ percentual aproximado de produção de cada material nesse processo é de $30 \%, 27 \%$, $32 \%$ e $5 \%$ respectivamente, além de $6 \%$ de um 'pedrisco' que é descartado, sendo considerado refugo. Após o material ser separado em cada malha das peneiras, o mesmo é depositado em silos, onde é considerado o módulo de estoque. Nesse módulo há seis silos: areia fina, areia média, areia grossa, filler, cimento e cal. No módulo de mistura/ensaque, as matérias primas para a fabricação da argamassa são misturadas pelo misturador dependendo do tipo de argamassa que se deseja fabricar e de acordo com a ordem de produção. Após esse processo a argamassa é ensacada pela ensacadeira manual em sacos de $25 \mathrm{~kg}$ cada, finalizando o processo de fabricação da argamassa até a etapa de ensaque (escopo final desse estudo).

A Figura 3 apresenta uma imagem da Fábrica Virtual desenvolvida, destacando que a modelagem foi realizada através do software Blender e a programação foi realizada com o software Unity 3D.

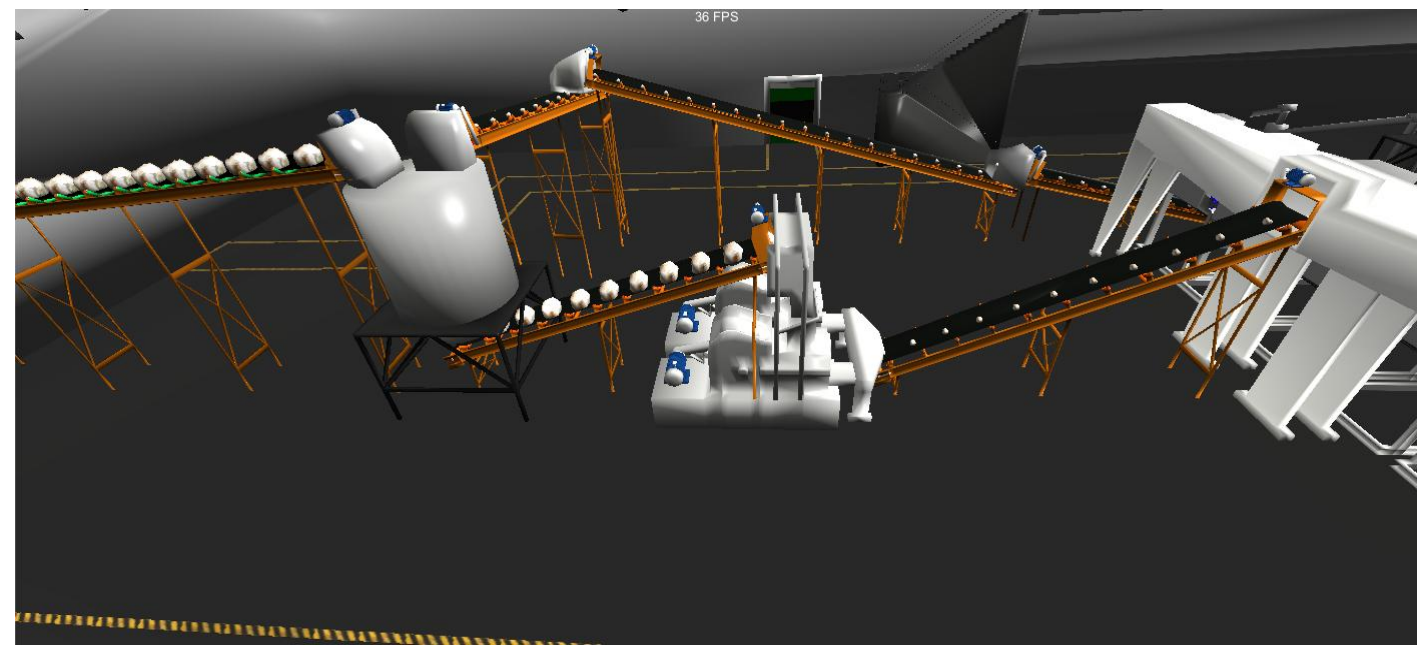

Figura 3 - Imagem da fábrica virtual desenvolvida

\subsection{Fase II - Levantamento dos custos e dados de produção}

Primeiramente foi levantado a quantidade total de equipamentos envolvidos em cada etapa do processo, assim como a especificação e potência de cada equipamento. Posteriormente foi realizado o levantamento do preço de mercado de cada equipamento através de pesquisa de mercado com orçamento de fornecedores e valores fornecidos pela fábrica modelo. Também foi levantado o percentual de depreciação anual de cada equipamento e ativo da fábrica. Com o preço, quantidade de 
equipamentos e o percentual de depreciação, foi possível definir o gasto mensal com depreciação total da fábrica de $\mathrm{R} \$ 80.253,33$.

Para os custos de manutenção, foi utilizado o valor total médio de $\mathrm{R} \$ 25.000,00$ por mês, valor esse que foi informado pela fábrica modelo. Outros custos levantados nessa etapa foram com materiais de consumo. Listou-se todos os materiais de consumo utilizados no processo, suas quantidades e custos, sendo o total consumido mensalmente de $\mathrm{R} \$ 33.104,00$.

$\mathrm{Na}$ etapa de levantamento dos custos, também se definiu a quantidade de mão-de-obra direta (MOD) e indireta (MOI) envolvida no processo, gerando dessa análise um organograma que pode ser visualizado no Apêndice C. A partir da definição da quantidade de MOD e MOI envolvida, definiu-se o valor do salário a ser pago para cada colaborador. Desse levantamento originou-se três tipos de salários para cada função, divididos em: menor, médio e maior. Utilizou-se como referência a média entre o menor e o médio salário, por se tratar de uma fábrica de médio porte. Para o cálculo do custo total, também foi considerado o gasto com $13^{\circ}$, férias, abono de férias, periculosidade, INSS, SAT/RAT e FGTS.

Por fim, também foi levantado a potência dos equipamentos, afim de calcular o custo mensal com energia elétrica. Foi utilizado como referência o valor pesquisado no site da CEEE considerando como classe industrial, sendo o valor do Quilowatt-hora $(\mathrm{kWh})$ de 0,511620 , mais $25 \%$ de alíquota de ICMS. Esse valor foi multiplicado pela potência em $\mathrm{kWh}$ e pela quantidade de horas utilizadas de cada equipamento, calculada através da multiplicação da capacidade instalada do equipamento pelo $\%$ de operação de cada equipamento no período analisado. Alguns equipamentos possuíam potência em cavalo-vapor (cv), que foi transformada em $\mathrm{kWh}$ multiplicando por 0,7355 .

Nessa fase também foi levantado os dados de produção adquiridos através de duas fontes: relatório de descrição do processo produtivo e modelagem da fábrica através do software ProModel. Os dados levantados nessa etapa foram: tempos de passagem do produto em cada equipamento, capacidade instalada da fábrica, quantidade de produção dos equipamentos em um período base modelado no ProModel (conforme Tabela 1), capacidades dos silos, produção total de argamassa durante o período base (um mês) adquirido via ProModel e percentual de operação de cada equipamento adquirido via ProModel (conforme Figura 4).

\begin{tabular}{cc} 
Tabela 1 - Dados de produção no período base \\
\hline PO & $\begin{array}{c}\text { Produção no período } \\
\text { base (ton/mês) }\end{array}$ \\
\hline Britador & 5790 \\
Pá carregadeira & 2826 \\
Moinho De Martelo & 3586 \\
Peneiras & 2703 \\
Secador & 2517 \\
Peneiras Paralelas & 2519 \\
Silo Areia Fina & 757 \\
Silo Areia Média & 677 \\
Silo Areia Grossa & 802 \\
Silo Filler & 133 \\
Silo Cimento & 547 \\
Silo Cal & 547 \\
Misturador & 1700 \\
Ensacadeira & 1696 \\
\hline
\end{tabular}




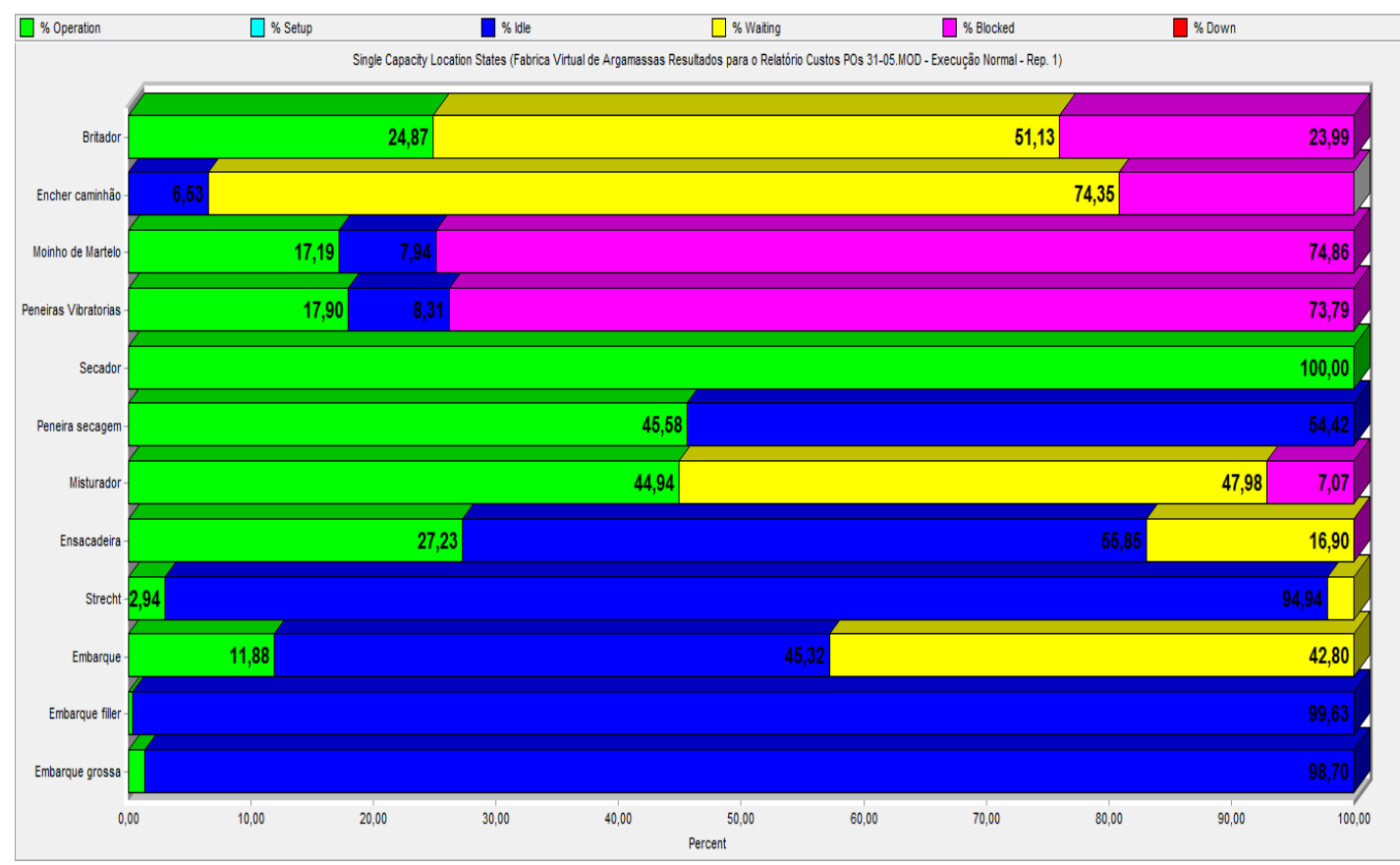

Figura 4 - Dados de percentual de operação por equipamento

Com os dados de produção foi possível visualizar através do gráfico gerado via ProModel, o percentual do tempo de operação de cada equipamento durante o período base analisado (em verde no gráfico), assim como o percentual de paradas por espera (em amarelo), paradas por ociosidade (em azul) e por superprodução (em rosa).

Analisando-se os dados percebe-se que o secador apresenta a sua operação em $100 \%$ do tempo analisado, demonstrando ser um possível gargalo do processo, pois está operando todo o tempo. $\mathrm{O}$ misturador e as peneiras vibratórias, antecessores ao Secador, apresentam um grau de ociosidade maior quando comparado com os outros equipamentos.

\subsection{Fase III - Implementação do Método UEP}

Primeiramente nessa fase o desafio foi dividir o processo de fabricação da argamassa em Postos Operativos (POs), considerando os dados de produção já levantados. O processo foi dividido em quatorze POs iniciando desde a explosão da jazida até a argamassa ensacada. Essa divisão pode ser explicada conforme Figura 5. Para a implementação do Método, foi necessário dividir a fábrica em três etapas: (i) fabricação da areia; (ii) estoque de material; e (iii) mistura e ensaque de argamassa, conforme Figura 6. 


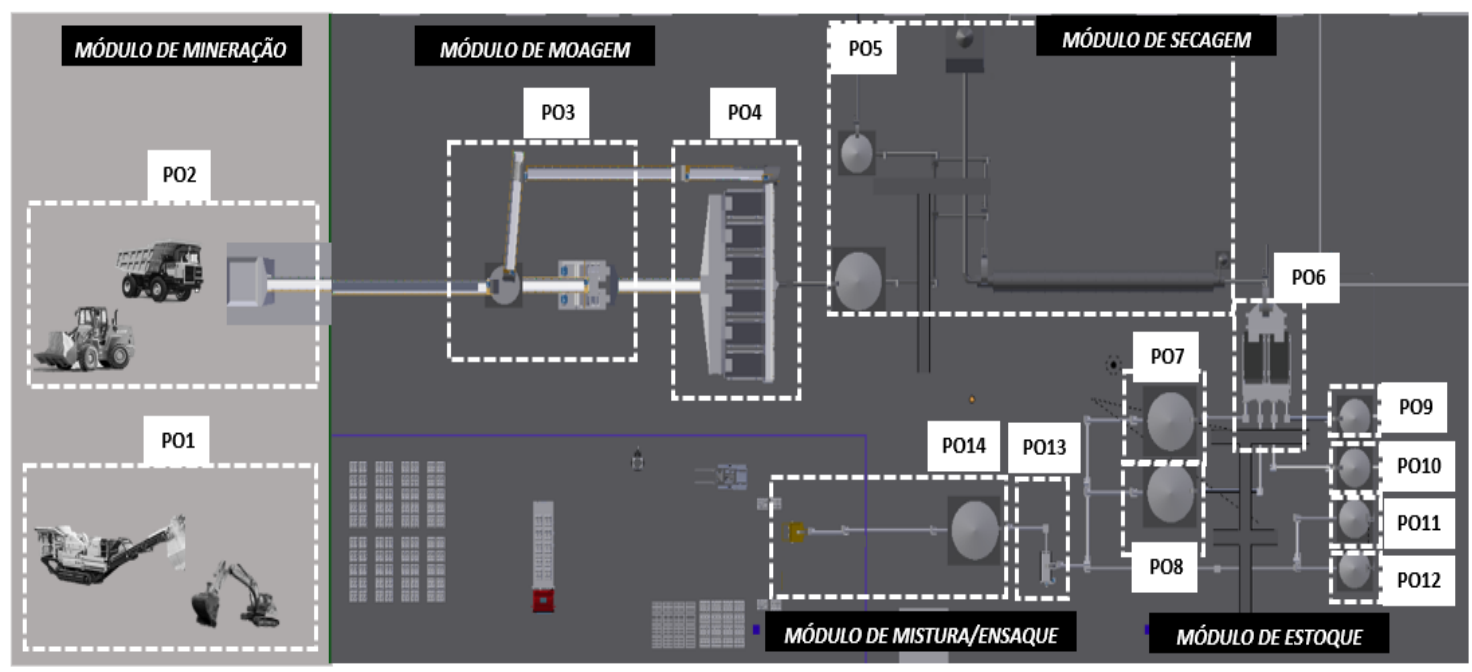

Figura 5 - Divisão do processo em Postos Operativos

\begin{tabular}{|c|c|c|}
\hline \multicolumn{3}{|c|}{ FABRICAÇÃO DA AREIA } \\
\hline $\mathrm{PO}$ & Descrição & QTD. \\
\hline \multirow[t]{2}{*}{ PO1 } & Britador de calcário & 1 \\
\hline & Escavadeira & 1 \\
\hline \multirow[t]{3}{*}{$\mathrm{PO} 2$} & Caminhão fora de estrada & 1 \\
\hline & Container de recebimento & 1 \\
\hline & Pá carregadeira & 1 \\
\hline \multirow[t]{3}{*}{ PO3 } & Esteira Transportadora & 2 \\
\hline & Moinhos de martelo & 2 \\
\hline & Silo do Moinho & 1 \\
\hline \multirow[t]{4}{*}{ PO4 } & Esteira de retorno & 1 \\
\hline & Esteira Transportadora & 2 \\
\hline & Peneiras vibratórias & 5 \\
\hline & Transportador sem-fim & 1 \\
\hline \multirow[t]{8}{*}{ PO5 } & Ciclone industrial & 1 \\
\hline & Container de descarga & 1 \\
\hline & Elevador de caneca & 3 \\
\hline & Gerador & 1 \\
\hline & Secador cilíndrico & 1 \\
\hline & Silo de material fino & 1 \\
\hline & Silo de material úmido & 1 \\
\hline & Transportador sem-fim & 2 \\
\hline \multirow[t]{2}{*}{ PO6 } & Peneiras vibratórias paralelas & 2 \\
\hline & Transportador sem-fim & 2 \\
\hline
\end{tabular}

\begin{tabular}{|c|c|c|}
\hline \multicolumn{3}{|c|}{ ESTOQUE DE MATERIAL } \\
\hline $\mathrm{PO}$ & Descrição & QTD. \\
\hline \multirow[t]{4}{*}{ PO7 } & Balança & 1 \\
\hline & Elevador de caneca & 2 \\
\hline & Silo de Areia fina & 1 \\
\hline & Transportador sem-fim & 2 \\
\hline \multirow[t]{4}{*}{ PO8 } & Balança & 1 \\
\hline & Elevador de caneca & 1 \\
\hline & Silo de Areia média & 1 \\
\hline & Transportador sem-fim & 2 \\
\hline \multirow[t]{4}{*}{ PO9 } & Balança & 1 \\
\hline & Elevador de caneca & 1 \\
\hline & Silo de Areia grossa & 1 \\
\hline & Transportador sem-fim & 1 \\
\hline \multirow[t]{4}{*}{ PO10 } & Balança & 1 \\
\hline & Elevador de caneca & 1 \\
\hline & Silo de Filler & 1 \\
\hline & Transportador sem-fim & 1 \\
\hline \multirow[t]{3}{*}{ P011 } & Balança & 1 \\
\hline & Silos de cimento & 1 \\
\hline & Transportador sem-fim & 1 \\
\hline \multirow[t]{3}{*}{ P012 } & Balança & 1 \\
\hline & Silo de Cal & 1 \\
\hline & Transportador sem-fim & 1 \\
\hline
\end{tabular}

\section{MISTURA E ENSAQUE DE ARGAMASSA}

\begin{tabular}{ccc} 
PO & Descrição & QTD. \\
\hline PO13 & Elevador de caneca & 1 \\
& Misturador & 1 \\
& Silo de argamassa & 1 \\
& Transportador sem-fim & 2 \\
\hline PO14 & Elevador de caneca & 3 \\
& Ensacadeiras manuais & 1 \\
& Transportador sem-fim & 5 \\
\hline
\end{tabular}

Figura 6 - Descrição de equipamentos por PO divididos em três etapas

Os POs 1 ao 6 foram considerados como a etapa de fabricação da areia, pois nessa etapa o esforço utilizado é focado para fabricação da areia, que é uma das matérias primas da argamassa. A partir do PO 7 ao 12, encontram-se os silos de armazenagem. Estes foram divididos em um PO por silo, sendo considerado como a etapa de estoque, porém nessa etapa o Método da UEP foi parcialmente utilizado, aderindo o conceito de Posto Operativo e o custo por hora (FIPO). Já os POs 13 e 14 foram considerados como a etapa de produção da argamassa, que é considerada como o produto final da fábrica.

Com os custos e dados de produção definidos e o processo divido em Postos Operativos, foi possível iniciar o cálculo do custo unitário através do método UEP. Para os POs 1 ao 6, foi determinado os Índices de Custo horário (FIPO) por PO, através da divisão da soma dos custos totais (R\$) por PO pela capacidade de produção instalada de cada PO (horas), obtendo o custo por hora de cada PO. Após isso, definiu-se o valor do Foto-Custo-Base, que é a multiplicação do FIPO pelo tempo de passagem em horas de uma tonelada do produto por cada PO. Somando-se todos os valores de Foto-Custo-Base de cada PO, obtém-se o valor de uma Unidade Esforço de Produção (UEP). Com 
esse valor calculou-se os Potenciais Produtivos por PO, através da divisão do FIPO pelo valor de uma UEP. Assim, multiplicando o Potencial Produtivo pelo tempo de passagem do produto em cada PO, obtendo o equivalente dos produtos em UEP. Somando o equivalente dos produtos em UEP de todos os POs dessa etapa de fabricação da areia (POs 1 ao 6), tem-se a quantidade equivalente dos produtos em esforço de produção, conforme ilustrado na Tabela 2. Por se tratar da passagem de somente um produto por essa etapa do processo produtivo (calcário que se torna areia), o equivalente do produto 1 UEP.

Tabela 2 - Método UEP aplicado à etapa de fabricação da areia

\begin{tabular}{|c|c|c|c|c|c|c|c|}
\hline & $\begin{array}{c}\text { P01 } \\
\text { Britador }\end{array}$ & $\begin{array}{c}\text { PO2 } \\
\text { Pá Escav. }\end{array}$ & $\begin{array}{c}\text { PO3 } \\
\text { Moinho } \\
\text { Mart. }\end{array}$ & $\begin{array}{c}\text { PO4 } \\
\text { Peneiras }\end{array}$ & Secador & $\begin{array}{c}\text { PO6 } \\
\text { Peneiras } \\
\text { Par. }\end{array}$ & \\
\hline MOD (R\$̦/mês) & 5849,88 & 1333,32 & 1333,32 & 1333,32 & 1333,32 & 1333,32 & \\
\hline MOI (R\$̦/mês) & 11444,00 & 9469,97 & 3478,91 & 3478,91 & 3478,91 & 3478,91 & \\
\hline Depreciação (R\$/mês) & 33666,67 & 7708,33 & 7300,00 & 14158,33 & 3861,67 & 5316,67 & \\
\hline Energ. Elétrica (R\$/mês) & 0,00 & 0,00 & 56,75 & 474,59 & 2164,99 & 53,08 & \\
\hline Mat. Consumo (R\$̦/mês) & 21100,00 & 100,00 & 6244,00 & 100,00 & 4660,00 & 100,00 & \\
\hline Manutenção (R\$̦/mês) & 2145,88 & 2624,12 & 303,35 & 505,41 & 4588,23 & 643,48 & \\
\hline TOTAL Custos (R\$̦/mês) & 74206,42 & 21235,74 & 18716,33 & 20050,56 & 20087,12 & 10925,46 & \\
\hline Capacidade de Produção (hrs/mês) & 228,00 & 228,00 & 480,00 & 480,00 & 480,00 & 480,00 & \\
\hline FIPO (R\$/h) & 325,47 & 93,139 & 38,992 & 41,772 & 41,848 & 22,761 & \\
\hline Tempo produto base ( $\mathrm{h} / \mathrm{ton}$ ) & 0,008 & 0,003 & 0,021 & 0,022 & 0,143 & 0,0649 & 1 UEP: \\
\hline Foto-Custo-Base & 2,712 & 0,321 & 0,848 & 0,904 & 5,978 & 1,478 & $\mathrm{R} \$ 12,24$ \\
\hline Potenc. Prod. (UEP/h) & 26,588 & 7,609 & 3,185 & 3,412 & 3,419 & 1,859 & \\
\hline
\end{tabular}

Para o cálculo de estoque de cada material nos POs 7 a 12, não foi utilizado o Método da UEP como um todo, somente o conceito da divisão em Postos Operativos e o custo hora por PO, sendo considerado cada silo um PO. Com a soma total dos custos por PO, dividiu-se esse valor pela capacidade instalada de cada PO, obtendo o custo hora. Dividindo esse valor pela capacidade de armazenagem de cada silo, tem-se o custo hora por tonelada armazenada, multiplicando esse valor pelo tempo que uma tonelada demora para passar pelo silo obtém-se finalmente o custo por silo para armazenar uma tonelada. A Tabela 3 apresenta este cálculo. Para os POs 13 e 14, referente a produção de mistura e ensaque de argamassa, foi utilizado a mesma lógica realizada para a fabricação da areia (POs 1 a 6), através do método da UEP, conforme já citado anteriormente e ilustrado na Tabela 4.

Tabela 3 - Custeio da estocagem de materiais

\begin{tabular}{|c|c|c|c|c|c|c|}
\hline & $\begin{array}{c}\text { PO7 } \\
\text { Silo Areia Fina }\end{array}$ & Silo Areia Média & $\begin{array}{l}\text { P09 } \\
\text { Silo Areia } \\
\text { Grossa }\end{array}$ & $\begin{array}{c}\text { P010 } \\
\text { Silo Filler }\end{array}$ & $\begin{array}{c}\text { P011 } \\
\text { Silo } \\
\text { Cimento }\end{array}$ & P012 \\
\hline MOD (R\$̦/mês) & 1333,32 & 1333,32 & 1333,32 & 1333,32 & 1333,32 & 1333,32 \\
\hline MOI (R\$/mês) & 3478,91 & 3478,91 & 3478,91 & 3478,91 & 3478,91 & 3478,91 \\
\hline Depreciação (R\$̦/mês) & 1330,00 & 1056,67 & 898,33 & 898,33 & 625,00 & 625,00 \\
\hline Energ. Elétrica ( $\mathrm{R} \$ / \mathrm{mês}$ ) & 204,14 & 120,49 & 98,25 & 98,25 & 19,58 & 19,58 \\
\hline Mat. Consumo (R\$̦/mês) & 100,00 & 100,00 & 100,00 & 100,00 & 100,00 & 100,00 \\
\hline Manutenção (R\$̦/mês) & 2295,67 & 2295,67 & 2295,67 & 2295,67 & 983,86 & 983,86 \\
\hline TOTAL Custos (R\$̣/mês) & 8742,04 & 8385,06 & 8204,48 & 8204,48 & 6540,67 & 6540,67 \\
\hline Capacidade de Produção (hrs/mês) & 480 & 480 & 480 & 480 & 480 & 480 \\
\hline FIPO (R\$/h) & 18,21 & 17,47 & 17,09 & 17,09 & 13,62 & 13,63 \\
\hline Tempo passagem (horas) & 38,14 & 40,88 & 8,15 & 62,31 & 23,59 & 29,01 \\
\hline Capacidade de armazenagem (ton) & 74 & 74 & 32 & 32 & 46 & 46 \\
\hline R\$/h.ton & 0,25 & 0,24 & 0,53 & 0,53 & 0,30 & 0,30 \\
\hline Custo por tonelada ( $\mathrm{R} \$$ /ton) & 9,39 & 9,65 & 4,35 & 33,28 & 6,99 & 8,59 \\
\hline \multicolumn{7}{|l|}{ Custo por tonelada INTEGRAL } \\
\hline (R\$/ton) & 12,20 & 12,55 & 5,66 & 43,27 & 9,08 & 11,17 \\
\hline
\end{tabular}


Tabela 4 - Método UEP aplicado na etapa de mistura e ensaque de argamassa

\begin{tabular}{|c|c|c|c|}
\hline & $\begin{array}{c}\text { P013 } \\
\text { Misturador }\end{array}$ & $\begin{array}{c}\text { P014 } \\
\text { Ensacadeira }\end{array}$ & \\
\hline MOD (R\$̦/mês) & 1333,32 & 9489,16 & \\
\hline MOI (R\$/mês) & 3478,91 & 3478,91 & \\
\hline Depreciação (R\$/mês) & 1015,00 & 1793,33 & \\
\hline Energ. Elétrica (R\$/mês) & 126,01 & 348,58 & \\
\hline Mat. Consumo (R\$/mês) & 100,00 & 100,00 & \\
\hline Manutenção (R\$̦/mês) & 2295,67 & 743,47 & \\
\hline TOTAL Custos (R\$/mês) & 8348,90 & 15953,46 & \\
\hline Capacidade de Produção (hrs/mês) & 480 & 480 & \\
\hline FIPO (R\$/h) & 17,39 & 33,24 & \\
\hline Tempo produto base (h/ton) & 0,090 & 0,058 & 1 UEP = \\
\hline Foto-Custo-Base & 1,565 & 1,920 & $\mathrm{R} \$ 3,49$ \\
\hline Potenc. Prod. (UEP/h) & 4,990 & 9,535 & \\
\hline
\end{tabular}

Para a definição do custo unitário de fabricação da areia (primeira etapa do processo), foi considerado a quantidade produzida no período base (um mês) nessa etapa do processo. Multiplicou-se as toneladas produzidas no período pelo equivalente dos produtos em UEP, obtendo o total de UEPs produzidos no período.

Para a definição dos custos totais de transformação do produto em um período base, foi considerado $30 \%$ a mais dos custos totais programados. Com o custo de transformação dos produtos, definiu-se o custo integral do UEP por tonelada de areia dividindo os custos de transformação pela produção do período, sendo o valor da areia de $\mathrm{R} \$ 85,33$ por tonelada.

Para a definição do custo integral de estoque de cada material foi considerado o custo por tonelada definido conforme Tabela 3, acrescido de 30\%. Para o cálculo do custo unitário de ensaque da argamassa, foi utilizado a mesma lógica definida para o cálculo do custo unitário de fabricação da areia, sendo o custo unitário integral de $\mathrm{R} \$ 18,62$ por tonelada ou $\mathrm{R} \$ 0,47$ por saco de $25 \mathrm{~kg}$, conforme Tabela 5.

Tabela 5 - Custo unitário Integral por tipo de produto

\begin{tabular}{ccc}
\hline & FABRICAÇÃO & ENSAQUE/MISTURA \\
& AREIA & ARGAMASSA \\
\hline PRODUÇÃo (ton/mês x UEP) & 2517 & 1696 \\
TOTAL Custos Programados (R\$/mês) & $165.221,62$ & $24.302,36$ \\
TOTAL Custos Gerados (R\$̦/mês) & $214.788,12$ & $31.593,07$ \\
Valor UEP INTEGRAL = CT/Produção total UEP & 85,33 & 18,62 \\
Custo INTEGRAL por Saco (R\$̦/saco) & - & 0,47 \\
\hline
\end{tabular}

Para o cálculo do custo de cada tipo de areia, foi somado o custo de fabricação da areia calculado através da UEP com o custo de estoque de cada tipo de areia, conforme ilustrado na Tabela 6.

Tabela 6 - Custo unitário Integral das areias fina e média

\begin{tabular}{cc}
\hline \multicolumn{2}{c}{ CUSTO INTEGRAL AREIA FINA (R\$/ton) } \\
\hline Custo INTEGRAL Areia (R\$/ton) & 85,33 \\
Custo de estoque Areia Fina & 12,20 \\
Custo Total Areia Fina & 97,54 \\
\hline CUSTO INTEGRAL AREIA MÉDIA (R\$/ton) \\
\hline Custo INTEGRAL Areia (R\$/ton) & 85,33 \\
Custo de estoque Areia média & 12,55 \\
Custo Total Areia média & 97,88 \\
\hline
\end{tabular}


Esse custo foi utilizado para calcular o Custo Padrão da argamassa, pois a areia é um dos componentes desse produto. A implementação do Custo Padrão com suas Fases será apresentada na próxima subseção.

Outra etapa da implantação do UEP foi a avaliação das medidas de desempenho, onde foi calculado a eficácia e eficiência da etapa do processo de fabricação da areia e mistura e ensaque da argamassa, assim como medida as capacidades teóricas, práticas, utilizadas e a produção total em UEP. Nessa etapa também foram calculadas as perdas por ociosidade, refugo e ineficiência.

$\mathrm{Na}$ etapa de fabricação da areia, o PO 5, demonstrou apresentar o maior percentual de eficiência entre os POs com 75\% de eficiência. Já na etapa de ensaque e mistura, o PO 13 referente ao misturador apresentou maior eficiência comparado com o PO 14 referente a ensacadeira, ambos com respectivas eficiências de $32 \%$ e $20 \%$. A Figura 7 apresenta os dados de eficiência para os POs analisados.

\begin{tabular}{|c|c|c|c|c|c|c|c|c|}
\hline & \multicolumn{6}{|c|}{ MEDIDAS DE DESEMPENHO - FABRICAÇÃO DA AREIA } & \multicolumn{2}{|c|}{ MEDIDAS DE DESEMPENHO- ENSAQUE } \\
\hline & P01 & P02 & PO3 & P04 & P05 & PO6 & P013 & P014 \\
\hline & Britador & Pá Escav. & Moinho Mart. & Peneiras & Secador & Peneiras Par. & Misturador & Ensacadeira \\
\hline Horas teóricas & 228 & 228 & 480 & 480 & 480 & 480 & 480 & 480 \\
\hline \% utilização & $76,00 \%$ & $74,35 \%$ & $17,19 \%$ & $17,90 \%$ & $100,00 \%$ & $45,58 \%$ & $92,92 \%$ & $42,13 \%$ \\
\hline Horas práticas (utilizada) & 173 & 170 & 83 & 86 & 480 & 219 & 446 & 202 \\
\hline \% refugo & $0,00 \%$ & $0,00 \%$ & $0,00 \%$ & $0,00 \%$ & $6,00 \%$ & $0,00 \%$ & $0,00 \%$ & $0,00 \%$ \\
\hline Produção total (hrs) & 48 & 10 & 78 & 59 & 381 & 164 & 153 & 98 \\
\hline Horas reais & 48 & 10 & 78 & 59 & 360 & 164 & 153 & 98 \\
\hline Potenc. Produtivo (UEP/h) & 26,59 & 7,61 & 3,19 & 3,41 & 3,42 & 1,86 & 4,99 & 9,53 \\
\hline Capacidade teórica (UEP) & 6062 & 1735 & 1529 & 1638 & 1641 & 893 & 2395 & 4577 \\
\hline Capacidade prática (UEP) & 4607 & 1290 & 263 & 293 & 1641 & 407 & 2226 & 1928 \\
\hline Produção real (UEP) & 1283 & 74 & 248 & 200 & 1229 & 304 & 763 & 935 \\
\hline Eficiência & $21,16 \%$ & $4 \%$ & $16 \%$ & $12 \%$ & $75 \%$ & $34 \%$ & $32 \%$ & $20 \%$ \\
\hline Eficácia & $28 \%$ & $6 \%$ & $94 \%$ & $68 \%$ & $75 \%$ & $75 \%$ & $34 \%$ & $48 \%$ \\
\hline Produtividade horária (UEP/h) & 27 & 8 & 3 & 3 & 3 & 2 & 5 & 10 \\
\hline Qtd toneladas produzidas & 5790 & 2826 & 3586 & 2703 & 2517 & 2519 & 1700 & 1696,48 \\
\hline
\end{tabular}

Figura 7 - Eficiência e Eficácia para os POs

A Figura 8 apresenta a comparação entre o custo das perdas por ociosidade, ineficiência e refugo entre os POs calculados através do Método da UEP.

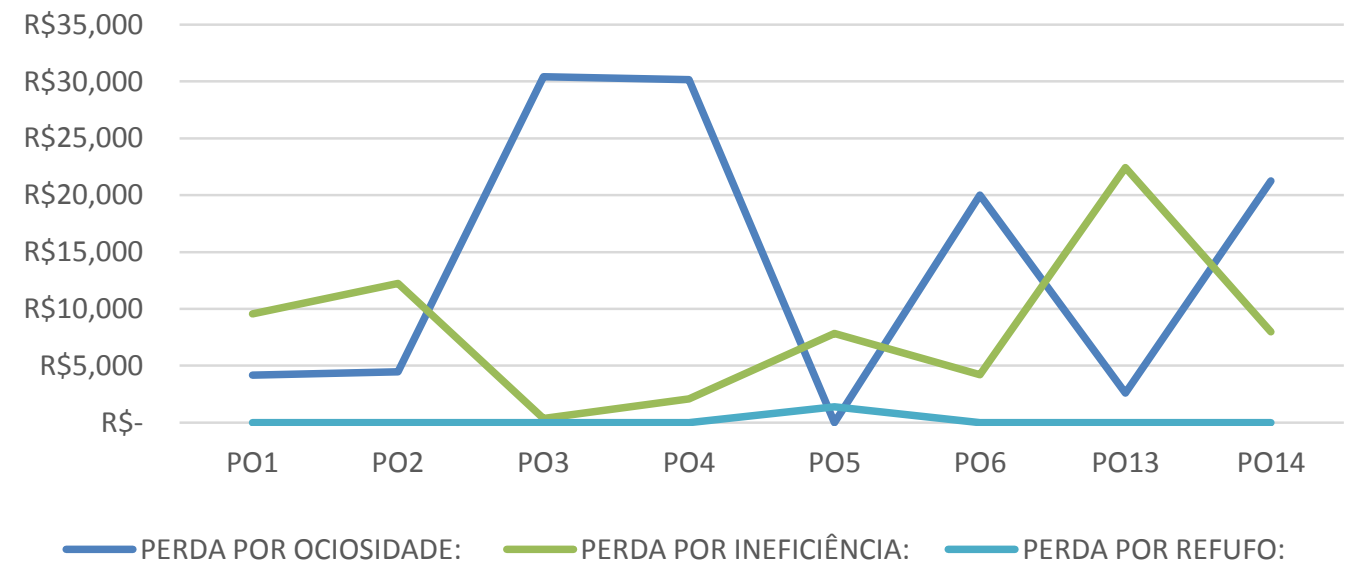

Figura 8 - Comparação entre o custo das perdas por PO

\subsection{Fase IV - Implementação do Custo Padrão}

Com a implementação do método UEP, foi possível definir o custo de fabricação da matériaprima areias, custo de estoque de cada material e o custo de mistura e ensaque da argamassa. Com o 
valor de fabricação da matéria prima areia fina e areia média definidas pelo método da UEP através da soma do custo da areia com o custo de estoque de cada tipo de areia, foi possível iniciar a implementação do Custo Padrão. O custo integral da matéria prima areia fina é de $\mathrm{R} \$ 97,54$ por tonelada, já o custo da matéria prima areia média é de $\mathrm{R} \$ 97,88$ por tonelada, conforme apresentado na Tabela 6. Para a definição do custo das demais matérias primas adquiridas por fornecedor, como o cimento e a cal, foi utilizado um valor de referência pesquisado, sendo de $\mathrm{R} \$ 300,00$ e $\$ 200,00$ por tonelada, respectivamente, mais a soma do custo de estoque calculado para cada matéria prima. Outro insumo para o cálculo do Custo Padrão é o custo da embalagem utilizado por cada saco de argamassa, sendo o valor de $\mathrm{R} \$ 0,64$ por embalagem, conforme informado pela fábrica modelo.

O próximo passo para a implementação do Custo Padrão foi a definição do traço utilizado em cada tipo de argamassa, esse foi definido pelo LESP através de pesquisa acadêmica com professor especializado na área. Foram utilizados valores estimados para esse estudo, pois o valor do traço depende de cada fabricante e é considerado informação sigilosa.

Para a fabricação de uma tonelada $(1000 \mathrm{~kg}$ ) de argamassa colante foram considerados 333,3 $\mathrm{kg}$ de cimento (MP1), 333,3 kg de cal (MP2) e 333,3 kg de areia fina (MP3). Para a fabricação de uma tonelada de argamassa de reboco foi considerado como necessário a mistura de $142,85 \mathrm{~kg}$ de cimento (MP1), 142,85 kg de cal (MP2), 142,85 kg de areia fina (MP3) e 571,4 kg de areia média (MP4). Para a argamassa de contrapiso foi considerado a utilização de $200 \mathrm{~kg}$ de cimento (MP1), $160 \mathrm{~kg}$ de areia fina (MP3) e $640 \mathrm{~kg}$ de areia média (MP4).

Com o traço definido e o custo de cada matéria prima definiu-se o valor do custo padrão para cada tipo de argamassa, conforme Tabela 7.

Tabela 7 - Cálculo do Custo Padrão de cada produto

\begin{tabular}{|c|c|c|c|c|c|c|c|c|}
\hline & \multicolumn{2}{|c|}{ Argamassa colante (P1) } & \multicolumn{3}{|c|}{ Argamassa de reboco (P2) } & \multicolumn{3}{|c|}{ Argamassa de contrapiso (P3) } \\
\hline & $\begin{array}{c}\text { Traço } \\
\text { (Kg/ton) }\end{array}$ & Custo (R\$/ton) & & Traço (Kg/ton) & Custo (R\$/ton) & & Traço (Kg/ton) & Custo (R\$/ton) \\
\hline MP1 & 333,33 & 103,02 & MP1 & 142,85 & 44,15 & MP1 & 200,00 & 61,82 \\
\hline MP2 & 333,33 & 70,38 & MP2 & 142,85 & 30,17 & MP2 & 0,00 & - \\
\hline MP3 & 333,33 & 32,51 & MP3 & 142,85 & 13,93 & MP3 & 160,00 & 15,61 \\
\hline MP4 & 333,33 & 32,62 & MP4 & 571,4 & 55,93 & MP4 & 640,00 & 62,64 \\
\hline \multicolumn{2}{|c|}{ (R\$/ton) } & 238,53 & \multicolumn{2}{|r|}{ (R\$/ton) } & 144,18 & \multicolumn{2}{|r|}{ (R\$/ton) } & 140,07 \\
\hline \multicolumn{2}{|c|}{$(\mathrm{R} \$ /$ saco) } & 5,96 & \multicolumn{2}{|r|}{$(\mathrm{R} \$ /$ saco) } & 3,60 & \multicolumn{2}{|r|}{ (R\$̦/saco) } & 3,50 \\
\hline \multicolumn{2}{|c|}{ Embalagem (R\$/saco) } & 0,64 & \multicolumn{2}{|c|}{ Embalagem (R\$̦/saco) } & 0,64 & \multicolumn{2}{|c|}{ Embalagem ( $\mathrm{R} \$$ /saco) } & 0,64 \\
\hline \multicolumn{2}{|c|}{ CUSTO UNITÁRIO } & 6 & \multicolumn{3}{|c|}{ CUSTO UNITÁRIO } & \multicolumn{2}{|c|}{ CUSTO UNITÁRIO } & 11 \\
\hline
\end{tabular}

O custo total unitário de fabricação de cada argamassa é formado pela soma do custo com as matérias primas mais os custos de transformação. O custo de matéria prima foi calculado através do custo de fabricação da areia, utilizando o método UEP, mais o custo de estoque de cada tipo de areia e o custo de compra do cal e cimento mais o custo de estoque de cada um. Para os custos de transformação foi considerado a soma dos custos de estoque de areia grossa e filler, oriundos do processo de fabricação de areia, menos a venda de cada um deles (R $\$ 45,00 / \mathrm{m}^{3}$ ) mais o custo de mistura e ensaque da argamassa, calculado através da UEP. Assim obtém-se o custo unitário da argamassa.

Com a esquemática de definição do custo total unitário definida e os devidos custos apurados, realizou-se uma pesquisa de preço conforme o tipo de argamassa vendida e o peso do saco considerado no modelo de $25 \mathrm{~kg}$, utilizando também como referência o preço de venda da fábrica modelo. Assim, com a definição do preço de venda de cada argamassa e os custos levantados, foi possível também, definir Margem Parcial Bruta Unitária de cada produto, diminuindo o preço de venda pelo custo unitário de cada produto, conforme ilustrado na Tabela 8. 
Tabela 8 - Custo unitário final, preço de venda e Margem Parcial Bruta Unitária por produto

\begin{tabular}{cccccc}
\hline Produto & $\begin{array}{c}\text { Custo da } \\
\text { MP } \\
\text { (R\$/saco) }\end{array}$ & $\begin{array}{c}\text { Custo de } \\
\text { Transformação } \\
\text { (R\$/saco) }\end{array}$ & $\begin{array}{c}\text { Custo Total Unitário } \\
\text { (R\$/saco) }\end{array}$ & $\begin{array}{c}\text { Preço venda } \\
\text { (R\$/saco) }\end{array}$ & $\begin{array}{c}\text { Margem Parcial } \\
\text { Bruta Unitária } \\
\text { (R\$/saco) }\end{array}$ \\
\hline Argamassa colante (P1) & 6,60 & 0,91 & 7,52 & 12,79 & 5,28 \\
Argamassa de reboco (P2) & 4,24 & 0,91 & 5,16 & 7,10 & 1,94 \\
Argamassa de contrapiso (P3) & 4,14 & 0,91 & 5,05 & 9,00 & 3,95 \\
\hline
\end{tabular}

A argamassa colante (P1) apresentou o maior Custo Total Unitário (CTU) de R \$ 7,52, que é a soma do custo da matéria prima de $\mathrm{R} \$ 6,60$ por saco e o Custo de Transformação de $\mathrm{R} \$ 0,91$ por saco. Mesmo com o maior custo a argamassa colante apresentou a maior Margem Parcial Bruta Unitária (MPBU) devido a sua diferença entre o preço e o CTU ser maior que as demais argamassas. A argamassa de reboco apresentou o segundo maior CTU de $\mathrm{R} \$ 5,16$, porém a MPBU de $\mathrm{R} \$ 1,94$ por saco vendido, já a argamassa de contrapiso apresentou o menor CTU de R\$ 5,05, porém com a segunda maior MPBU de R \$3,95 por saco.

\subsection{Fase V - Modelagem e análise da produção}

Com o Custo Total Unitário de cada argamassa definido foi possível avaliar o impacto de diferentes cenários, considerando a alteração das variáveis, no custo de fabricação da argamassa. Foi escolhido outros dois cenários (além do cenário já trabalhado), para avaliar o impacto no sistema de custeio da mudança de equipamentos considerados gargalo em cada etapa analisada. Na etapa de fabricação de areia, constatou-se que o PO5, referente ao secador, possui a maior eficiência, indicando ser um possível gargalo dessa etapa do processo, então, se decidiu por criar um cenário variando o número de secadores para 2 a fim de e avaliar o impacto no Sistema de custeio, em que foi chamado de cenário 2, sendo o cenário $1 \mathrm{o}$ detalhado anteriormente neste estudo. Outro ponto avaliado no cenário inicial foi referente a etapa de mistura e ensaque de argamassa, o PO13, referente ao misturador, apresentou maior eficiência nessa etapa, indicando também ser o possível gargalo dessa fase. Também, verificou-se que o misturador em média dispende 47,98\% do tempo esperando para encher, ao invés de estar produzindo. Assim, se decidiu por criar um cenário incluindo um buffer anterior ao misturador, enquanto o misturador estiver exercendo sua função, o buffer estará enchendo, reduzindo bruscamente a perda por espera do misturador. Esse cenário foi chamado de cenário 3. Com esses três cenários definidos em conjunto com o LESP, gerou-se os gráficos de produção e percentual de operação de cada cenário através do ProModel.

Para o cenário 2, foi necessário inserir no processo um cilindro secador, um ciclone industrial e um transportador sem-fim a mais. Para o cenário 3, foi necessário agregar no processo um buffer ou container de uma tonelada, um transportador sem-fim e um elevador de caneca, agregando custo de depreciação dos equipamentos e energia elétrica em ambos os processos.

Após gerar os três cenários, alterando-se as variáveis descritas, foi possível avaliar o impacto de cada um deles no sistema de custeio, conforme Tabela 9. 
Tabela 9 - Análise comparativa entre os diferentes cenários

\begin{tabular}{|c|c|c|c|c|c|c|c|c|c|}
\hline & \multicolumn{3}{|c|}{ Cenário 1 (Inicial) } & \multicolumn{3}{|c|}{ Cenário 2 ( 2 secadores) } & \multicolumn{3}{|c|}{ Cenário 3 (buffer) } \\
\hline Produção de areia (ton) & \multicolumn{3}{|c|}{2519} & \multicolumn{3}{|c|}{4831} & \multicolumn{3}{|c|}{2519} \\
\hline Produção de argamassa (ton) & \multicolumn{3}{|c|}{1696} & \multicolumn{3}{|c|}{1696} & \multicolumn{3}{|c|}{2767} \\
\hline Gasto perda por ineficiência ( $\mathrm{R} \$$ /mês) & \multicolumn{3}{|c|}{$74.076,81$} & \multicolumn{3}{|c|}{$49.619,95$} & \multicolumn{3}{|c|}{$71.972,10$} \\
\hline Gasto perda por ociosidade (R\$/mês) & \multicolumn{3}{|c|}{$126.103,40$} & \multicolumn{3}{|c|}{$44.901,68$} & \multicolumn{3}{|c|}{$114.521,06$} \\
\hline Gasto perda por refugo (R\$/mês) & \multicolumn{3}{|c|}{$1.841,09$} & \multicolumn{3}{|c|}{947,31} & \multicolumn{3}{|c|}{$1.841,09$} \\
\hline Custos de transformação ( $R \$$ /mês) & \multicolumn{3}{|c|}{$236.141,38$} & \multicolumn{3}{|c|}{$240.013,48$} & \multicolumn{3}{|c|}{$203.262,79$} \\
\hline Custo unitário Areia fina ( $\mathrm{R} \$$ /ton) & \multicolumn{3}{|c|}{97,54} & \multicolumn{3}{|c|}{57,72} & \multicolumn{3}{|c|}{97,53} \\
\hline \multirow[t]{2}{*}{ Custo unitário Areia média ( $R \$ /$ ton) } & \multicolumn{3}{|c|}{97,88} & \multicolumn{3}{|c|}{58,04} & \multicolumn{3}{|c|}{97,79} \\
\hline & P1 & P2 & P3 & P1 & $\mathrm{P} 2$ & P3 & $\mathrm{P} 1$ & $\mathrm{P} 2$ & P3 \\
\hline Preço de venda ( $R \$ /$ Saco) & 12,792 & 7,100 & 9,000 & 12,792 & 7,100 & 9,000 & 12,792 & 7,100 & 9,000 \\
\hline Custo unitário MP (R\$/saco) & 6,603 & 4,245 & 4,142 & 5,938 & 3,533 & 3,345 & 6,602 & 4,243 & 4,140 \\
\hline Custo unitário de transformação ( $\mathrm{R} \$$ /saco) & 0,913 & 0,913 & 0,913 & 0,886 & 0,886 & 0,886 & 0,747 & 0,747 & 0,747 \\
\hline Custo unitário TOTAL (R\$/saco) & 7,516 & 5,157 & 5,055 & 6,824 & 4,419 & 4,231 & 7,348 & 4,989 & 4,887 \\
\hline Margem parcial bruta unitária ( $\mathrm{R} \$ \mathrm{saco})$ & 5,275 & 1,943 & 3,945 & 5,967 & 2,681 & 4,769 & 5,443 & 2,111 & 4,113 \\
\hline Produção em sacos de argamassa (sacos) & \multicolumn{3}{|c|}{67840} & \multicolumn{3}{|c|}{67840} & \multicolumn{3}{|c|}{110680} \\
\hline \% de produção por tipo & $40 \%$ & $30 \%$ & $30 \%$ & $40 \%$ & $30 \%$ & $30 \%$ & $40 \%$ & $30 \%$ & $30 \%$ \\
\hline Produção por tipo de argamassa (sacos) & 27136 & 20352 & 20352 & 27136 & 20352 & 20352 & 44272 & 33204 & 33204 \\
\hline Venda total em R\$ & $347.114,67$ & $144.499,20$ & $183.168,00$ & $347.114,67$ & $144.499,20$ & $183.168,00$ & $566.312,67$ & $235.748,40$ & $298.836,00$ \\
\hline Custo total em R\$ & $203.960,39$ & $104.963,24$ & $102.869,87$ & $185.187,67$ & $89.935,89$ & $86.110,00$ & $325.329,24$ & $165.671,30$ & $162.254,52$ \\
\hline Lucro Parcial Bruto por produto em $\mathrm{R} \$$ & $143.154,27$ & $39.535,96$ & $80.298,13$ & $161.926,99$ & $54.563,31$ & $97.058,00$ & $240.983,43$ & $70.077,10$ & $136.581,48$ \\
\hline LUCRO PARCIAL BRUTO TOTAL em R\$ & \multicolumn{3}{|c|}{$R \$ 262.988$} & \multicolumn{3}{|c|}{$\mathrm{R} \$ 313.548$} & & $\mathrm{R} \$ 447.642$ & \\
\hline
\end{tabular}

Analisando somente sob o ponto de vista do custo unitário, o cenário 2 possui o menor CUT da argamassa com um valor de $\mathrm{R} \$ 6,82$ para a $\mathrm{P} 1, \mathrm{R} \$ 4,41$ para a $\mathrm{P} 2$ e $\mathrm{R} \$ 4,23$ para a $\mathrm{P} 3$, conforme Tabela 9. Esse custo menor acontece devido ao aumento da produção de areia ocorrido pela duplicação do secador que é gargalo nessa etapa, mesmo aumentando o custo do PO5, o aumento de produção de 2.519 para 4.831 toneladas dilui o custo unitário de fabricação da areia, que faz parte da formação do custo de matéria prima da argamassa, assim diminuindo o custo unitário da argamassa. Porém, mesmo produzindo mais areia com a inserção do secador, o output, de argamassa continua sendo o mesmo do cenário 1 de 1.696 toneladas por mês, devido ao tamanho do estoque dos silos e quem demandar o output ser o misturador. Já no cenário 3, apesar de a alteração no cenário não gerar o menor custo unitário do produto, essa alteração gera um output maior de argamassa, de 1.696 para 2.767 toneladas no período base. Considerando que o total vendido de argamassa seja o mesmo do total produzido no período, o cenário 3 apresenta maior lucratividade comparando com os demais cenários, com o valor do lucro bruto de $\mathrm{R} \$ 447.642,00$ no mês base, representando $\mathrm{R} \$ 184.653,64$ a mais de lucratividade que o cenário 1 e $\mathrm{R} \$ 134.093,70$ a mais que o cenário 2. Assim, sob o aspecto de custo unitário o cenário 2 apresenta o menor custo, porém sob o aspecto de lucratividade da fábrica o cenário 3 apresenta maior retorno considerando que produz uma quantidade maior de argamassa, com um custo menor que o cenário 1 , porém maior que o cenário 2 .

\section{Considerações finais}

Conforme o objetivo geral deste trabalho, foi estruturado o sistema de custeio para a fábrica desenvolvida em Realidade Virtual pelo Laboratório de Engenharia de Sistemas de Produção da PUCRS. Assim como os objetivos específicos de análise de cenários e do impacto dos mesmos no sistema de custeio foram realizados com êxito, gerando uma base de dados com todos os custos envolvidos no processo de produção da argamassa, servindo para utilização do LESP para fins acadêmicos. E os cenários realizados podendo ser utilizados como forma de ensino aos estudantes da Engenharia de Produção da universidade na disciplina de Custos Gerenciais.

$\mathrm{O}$ estudo demonstrou a importância de não somente analisar o processo produtivo sob o impacto dos custos, da produção ou da venda isolada, mas analisar a lucratividade como um todo, tendo uma visão sistêmica dos impactos gerados com a definição de um melhor cenário fabril. $\mathrm{O}$ estudo também gerou como output a forma de definição do custo total unitário da argamassa, que apesar de a fábrica poder ser considerada como monoprodutora (pois a diferença dos três produtos está somente no traço utilizado), a estruturação do sistema de custeio com a definição do custo unitário demonstrou-se complexa, também por se tratar de um processo contínuo. O desenvolvimento do sistema de custeio com a flexibilidade de mudança no processo produtivo comprovou a importância de se estruturar um sistema de custeio antes mesmo de realizar a fabricação da planta fabril, podendo 
simular qual a melhor disposição de equipamentos e o impacto não somente na produção, mas nos indicadores financeiros.

Sugere-se para trabalhos futuros uma abordagem entre a precificação e a extrapolação da demanda a longo prazo, mitigando o impacto da lucratividade, alterando ambas as variáveis, além do custo. Sugere-se ainda, o levantamento dos custos das áreas indiretas como vendas, área administrativa e logística, por não se tratar do escopo dos métodos de custeio aplicados, não foi abordado nesse trabalho os custos envolvidos com essas áreas. Para isso sugere-se a aplicação do método de custeio $\mathrm{ABC}$ para o mapeamento e alocação dos custos indiretos.

\section{Referências}

BARATA, P. N. A. Projeto e implementação de um sistema de autoria para animações, simulações e treinamento em realidade virtual. Dissertação (Mestrado em Engenharia). Universidade Federal do Pará - UFPA, 2010.

BEUREN, I. M.; SOUSA, M. A. B.; RAUPP, F. M. Um estudo sobre a utilização de sistemas de custeio em empresas Brasileiras. In: CONGRESSO INTERNACIONAL DE CUSTOS, 2003, Punta del Este, Uruguay. Anais... Punta del Este, 2003.

BORNIA. A.C. Análise gerencial de custos: Aplicação em empresas modernas. $3^{\text {a } e d i c ̧ a ̃ o . ~ P o r t o ~}$ Alegre: Atlas, 2010.

CAMBRUZZI, D.; BALEN, F. V.; MOROZINI, J. F. Unidade de Esforço de Produção (UEP) como Método de Custeio: Implantação de Modelo em uma Indústria de Laticínios. ABCustos Associação Brasileira de Custos, v.4, n.1, 2009.

FADANELLI, V.G. A utilização do método da unidade esforço de produção como modelo de gestão de custos - o caso de empresa do ramo metalúrgico. 2007. Dissertação (Mestrado Profissional Engenharia de Produção) - Faculdade de Engenharia, PPGEP/UFRGS, Porto Alegre, 2007.

FILOMENA, T. P.; ANZANELLO, M. J.; KLIEMANN NETO, J. F.; DUFFEY, M. R.; CAMPOSNÁÑEZ, E. Manufacturing feature-based cost management system: a case study in Brazil. Production Planning \& Control, V. 22, n. 4, 2011.

GOULDING, J.; NADIM, W.; PETRIDIS, P.; ALSHAWI, M. Construction industry offsite production: A virtual reality interactive training environment prototype. Advanced Engineering Informatics, v. 26, pg. $103-116,2012$.

HAFNER, P.; HAFNER, V.; OVTCHAROVA, J. Teaching Methodology for Virtual Reality Practical Course in Engineering Education. Procedia computer Science, n.25, p. 251-260, 2013.

HAGUENAUER, C. J.; CUNHA, G.G.; CORDEIRO FILHO, F.; ARAUJO, M. C. M.; ALMEIDA, L. S. M. P.; LOHMANN, A. F. Projeto Museu Virtual: criação de ambientes virtuais com recursos e técnicas de Realidade Virtual. Revista Realidade Virtual, v.1, n.2, 2008.

HARREL, C. R.; PRICE, R. N. Simulation Modeling using ProModel Technology. Proceedings of Winter Simulation Conference, 2003.

HUI, L.; YUNMIN, Z.; YUHONG, D. The Research of Oil Extraction Engineering Based on Virtual Reality. AASRI Procedia, v. 1, pg. 189-195, 2012.

KAUARK, F. S.; MANHÃS, F. C.; MEDEIROS, C. H. Metodologia de pesquisa: um guia prático. Itabuna: Via litterarum, 2010.

KLINGSTAM, P.; GULLANDER, P. Overview of simulation tools for computer-aided production engineering. Computers in Industry, v.38, I.2, 1999. 
KUNH, P. D.; FRANCISCO, A. C.; KOVALESKI, J. L. Aplicação e Utilização do Método Unidade de Esforço de Produção (UEP) para Análise Gerencial e como Ferramenta para o Aumento da Competitividade. Revista Produção On Line, v.11, n.3, p. 688-706, 2011.

LIMA, F.; PRADO, A. C.; MASSOTE, A. A.; LEONARDI, F. An experience of Teaching Industrial Automation for Industrial Engineering Undergraduate Students. IEEE International Conference on Teaching, Assessment, and Learning for Engineering. Hong Kong, 2012.

MARCONI, M. A.; LAKATOS, E. M. Técnicas de Pesquisa. 4a ed. São Paulo: Atlas, 1999.

MARTINS, V. F.; GUIMARÃES, M. P. Desafios para o uso de Realidade Virtual e Aumentada de maneira efetiva no ensino. In: DEsafIE! - I Workshop de Desafios da Computação Aplicada à Educação - XXXII Congresso da Sociedade Brasileira de Computação, 2012, Curitiba. Anais do DEsafIE! - I Workshop de Desafios da Computação Aplicada à Educação.

MONNERAT, M. C.; ROMANO, P. S. R.; GRILLO, O. N.; HAGUENAUER, C. J.; AZEVEDO, S. A. K.; CUNHA, G.G. The Dinos Project: a virtual approach of a real exhibition. Revista Realidade Virtual, v.5, n.1, p.94-18, 2012.

MUJBER, T. S.; SZECSI, T.; HASHMI M.S.J. Virtual reality applications in manufacturing process simulation. Journal of Materials Processing Technology, n.155, p. 1834-1838, 2004.

NETTO, A. V.; TAHARA, C. S.; PORTO A. J. V.; FILHO E. V. G. Realidade virtual e suas aplicações na área de manufatura, treinamento, simulação e desenvolvimento de produto. Revista Gestão \& Produção, v.5, n.2, p. 104-116, 1998.

POWELL, L. C. R. Integrating Practice into Engineering Education. Proceedings of American Society for Engineering Education Annual COnference \& Exposition, 2005.

RAINSFORD, C. A. M. E. Technology-enhanced learning: an Irish Industry perspective. Journal of European Industrial Training 29, v. 6, pg. 257 - 471, 2005.

SAKAMOTO, F.T.C. A gestão da produção e gestão de custo através da UP- Unidade de Produção: fase pós-implantação da UP na Seara Alimentos S.A. In: XXIII ENCONTRO NACIONAL DE ENGENHARIA DE PRODUÇÃO (ENEGEP), Ouro Preto, 2003. Anais... Ouro Preto, 2003.

SEVERINO, J. A. Metodologia do trabalho científico. 23 ed. São Paulo: Cortez, 2007.

SILVA, R. C.; SILVA, A. R. Tecnologias para construção de mundos virtuais: um comparativo entre opções existentes no mercado. FAZU em Revista, n.8, p.211-215, 2011

SUNG, R. C. W.; RITCHIE, J. M.; ROBINSON, G.; DAY, P. N.; CORNEY, J. R.; LIM, T. Automated design process modelling and analysis using immersive virtual reality. Computer-Aided Design, v. 41, pg. 1082 - 1094, 2009.

TIRUVANNAMALAI, R.; WHITMAN, L.; CHERAGHI H.; RAMACHANDRAN A. An interactive web-based virtual factory model for teaching production concepts. In: Proceedings of the 2004 Industrial Engineering Research Conference, 2004, Houston, TX.

VERGARA, S. C. Métodos de pesquisa em administração. São Paulo: Atlas, 2005.

WERNKE, R. Gestão de custos: uma abordagem prática. 2a . ed. São Paulo: Atlas, 2004.

WHITMAN, L.; CHAPARRO B. Efficacy of Virtual Models in a Production Systems Course. In: Proceedings of the 2006 Midwest Section Conference of the American Society for Engineering Education, 2006, Kansas City.

ZONNATO, V. C. S.; SOARES, F. B. C.; BARTZ D.; KAPPEL R. S. Aplicação do método UEP (Unidade de Esforço de Produção) na determinação dos custos de reciclagem de embalagens plásticas. Revista Inovação, Gestão e Produção, v.2, n.11, 2010.

XIAOQIANG, Z.; AN, W.; JIANZHONG, L. Design and application of virtual reality system in fully mechanized mining face. Procedia Engineering, v. 26, pg. 2165 - 2172, 2011. 